\title{
A New Model for Simulating TSS Washoff in Urban Areas
}

\author{
E. Crobeddu and S. Bennis \\ Département de Génie de la Construction, École de Technologie Supérieure, 1100 rue Notre-Dame Ouest, \\ Montréal, QC, Canada H3C 1 K3 \\ Correspondence should be addressed to S. Bennis, saad.bennis@etsmtl.ca
}

Received 2 June 2010; Revised 13 December 2010; Accepted 24 January 2011

Academic Editor: Artemi Cerda

Copyright (C) 2011 E. Crobeddu and S. Bennis. This is an open access article distributed under the Creative Commons Attribution License, which permits unrestricted use, distribution, and reproduction in any medium, provided the original work is properly cited.

\begin{abstract}
This paper presents the formulation and validation of the conceptual Runoff Quality Simulation Model (RQSM) that was developed to simulate the erosion and transport of solid particles in urban areas. The RQSM assumes that solid particle accumulation on pervious and impervious areas is infinite. The RQSM simulates soil erosion using rainfall kinetic energy and solid particle transport with linear system theory. A sensitivity analysis was conducted on the RQSM to show the influence of each parameter on the simulated load. Total suspended solid (TSS) loads monitored at the outlet of the borough of Verdun in Canada and at three catchment outlets of the City of Champaign in the United States were used to validate the RQSM. TSS loads simulated by the RQSM were compared to measured loads and to loads simulated by the Rating Curve model and the Exponential model of the SWMM software. The simulation performance of the RQSM was comparable to the Exponential and Rating Curve models.
\end{abstract}

\section{Introduction}

During high-intensity rainfall events, the discharge of untreated storm water and wastewater occurs into receiving waters when the capacity of combined sewer systems (CSSs) is exceeded. The combined sewer overflow events (CSOs) generate high concentrations of microbial pathogens, biochemical oxygen demand, total suspended solids, and other pollutants into receiving waters [1]. Minimizing the impact of watercourse pollution through intercepting the maximum amount of pollutant particles is of increasing concern to municipalities. Knowledge of the wet weather pollutograph seems essential in order to maximize sewer network pollutant interception in real-time management. However, it is difficult to predict the pollutograph associated with each pollutant. Total suspended solid (TSS) load is considered the main vector of runoff water pollution in urban areas $[2,3]$. Consequently, a good estimation of water pollution can be given knowing the concentration of suspended particles in storm water [4].

The cycle of solid particles in an urban area is a complex process that involves solid particle buildup in the catchment during dry weather periods followed by solid particle washoff during wet weather periods.
The most frequently used buildup models are asymptotic, most often derived from the Alley and Smith [5] exponential model used in the Storm Water Management Model (SWMM) software, but may also be linear [6].

The process of soil washoff in urban areas is often represented with conceptual approaches. The simplest conceptual model is the Rating Curve model $[7,8]$ that links suspended particle load to runoff rate. The SWMM software Exponential model [7] calculates both the suspended particle load washed off by the runoff flow and the mass of accumulated particle. Several models take the accumulated particle mass into consideration, including the STORM software washoff model [9], the model developed by Moys et al. [10] for the MOSQUITO software, the HSPF model [11], and the model developed by Zug et al. [12] for the HORUS software. Recent advances have led to the development of deterministic models $[13,14]$ that offer the advantage of describing the physical phenomena involved in soil washoff. However, their use requires data that are either rarely available or difficult to obtain. The suspended particle load may also be calculated using statistical models [15] that have a validity limited to the sites where they were developed [16].

This paper presents a new conceptual washoff model for urban areas. The results of the proposed model will be 
validated using on-site TSS measurements and compared with the results of both the Exponential and Rating Curve models. Moreover, a sensitivity analysis of the model will be performed.

\section{The Buildup Process}

2.1. Problems Related to Particle Buildup. Sources of solid particles include industrial activities, transportation, and erosion due to climactic action. During dry weather, particles accumulate on urban areas. The particle accumulation is a complex physical process which has been described by three distinct approaches. The first one assumes a time varying accumulation of solid particles. The mass of accumulated solid particles is a function of the elapsed time since the last rainfall event. This accumulation is generally described by using the following equation:

$$
\frac{d \mathrm{Ma}(t)}{d t}=\mathrm{ACCU}-\operatorname{DISPMa}(t)
$$

where Ma represents the mass of accumulated solid particles $(\mathrm{kg})$, ACCU represents the daily rate of accumulation $(\mathrm{kg} / \mathrm{D})$, and DISP, rate of decay due to non-runoff processes $\left(\mathrm{d}^{-1}\right)$.

The particle buildup occurs during dry weather. The particle mass grows exponentially up to an asymptotic value. Sartor et al. [17] demonstrated that maximum buildup is reached after approximately ten days, but this value varies greatly according to the studied area. Linear relationships between accumulated mass of solid particles and time have also been developed. They provided good results in some studies [18]. The second approach assumes that buildup is an instantaneous process. The mass of accumulated particles is instantaneously regenerated at the end of a rainfall event. This approach allows for a simplification of the washoff model formulation. Finally, the third approach assumes that the accumulated mass of solid particles is infinite. This approach also simplifies the washoff model formulation.

2.2. Selecting a Buildup Model. Urban catchments are a juxtaposition of pervious and impervious areas. Pervious areas are natural or landscaped granular soils. They can be seen as infinite reserves of solid particles. Therefore, they can be described by an infinite buildup approach.

Solid particle accumulation on impervious areas is not fully understood. Indeed, Gromaire [19] demonstrated the existence of washoff on urban roads, and Sartor et al. [17] showed that buildup occurs during dry weather. On the other hand, the statistical analyses of Kanso et al. [20] showed that dry weather has no effect on the buildup process. Furthermore, the analyses conducted by Butler et al. [21] on water samples monitored in six different sites revealed no causal relationship between the accumulated solid particle mass and the load of solid particles in storm water. Consequently, impervious areas seem more likely to behave like a reservoir, where the loss of solid particles is balanced by an equivalent deposit of solid particles. Indeed, solid particle production by climatic action and human activities does not cease during a rainfall event.
Contradictions among authors on the nature of the buildup process on impervious areas can be explained by the complexity of the physical process involved. Further research seems to be necessary to fully understand buildup process.

\section{Formulation of the Runoff Quality Simulation Model (RQSM)}

3.1. Assumptions. The Runoff Quality Simulation Model (RQSM) is based on the following physical assumptions:

(i) infinite buildup over both impervious and pervious areas;

(ii) time of concentration for solid and liquid particles is equal;

(iii) uniform rainfall intensity over the catchment area;

(iv) the impulse response function of a catchment area is rectangular shaped and ends at the time of concentration.

3.2. Solid Particle Erosion Model. Young and Wiersma [22] showed that rainfall kinetic energy is the main cause of solid particle detachment. Salles et al. [23] furthermore demonstrated analytically that the most appropriate relationship to use for calculating rainfall kinetic energy as a function of its intensity is the following:

$$
\mathrm{KE}(t)=\alpha I(t)^{\beta},
$$

where KE represents rainfall kinetic energy $\left(\mathrm{J} \cdot \mathrm{m}^{2} \cdot \mathrm{h}^{-1}\right), \alpha$ and $\beta$, the parameters related to the microscopic processes of raindrop formation, and $I$, the intensity of the rain $(\mathrm{mm} / \mathrm{h})$. Furthermore, Salles et al. [23] showed that (2) was physically realistic for a value of $\alpha$ between 9.2 and 13.5 inclusively and for a value of $\beta$ between 1 and 1.4 inclusively.

The infinite accumulation assumption leads to expression of the erosion intensity according to the following formula:

$$
\mathrm{mp}_{\mathrm{imp}}(t)=\frac{\mathrm{Kp}}{3600}\left(\alpha I(t)^{\beta}\right),
$$

where $m p_{i m p}$ represents the erosion intensity of solid particles for impervious areas $\left(\mathrm{kg} \cdot \mathrm{m}^{-2} \cdot \mathrm{s}^{-1}\right)$ and $\mathrm{Kp}$ imp, the erosion rate of solid particles for impervious areas $(\mathrm{kg} / \mathrm{d})$.

The solid particle erosion of pervious areas is also a function of rainfall kinetic energy. It begins when the rainfall intensity is higher than the infiltration capacity of the pervious areas. The erosion intensity of pervious areas is computed with the following formula:

$$
\operatorname{mp}_{\mathrm{per}}(t)=\frac{\mathrm{Kp}_{\mathrm{per}}}{3600}\left[\alpha(I(t)-f(t))^{\beta}\right],
$$

where $m p_{\text {per }}$ represents the erosion intensity of solid particles for pervious areas $\left(\mathrm{kg} \cdot \mathrm{m}^{-2} \cdot \mathrm{s}^{-1}\right), \mathrm{Kp}$ per, erosion rate of solid particles for the pervious areas $(\mathrm{kg} / \mathrm{J})$, and $f$, the infiltration capacity of the pervious areas $(\mathrm{mm} / \mathrm{h})$. 


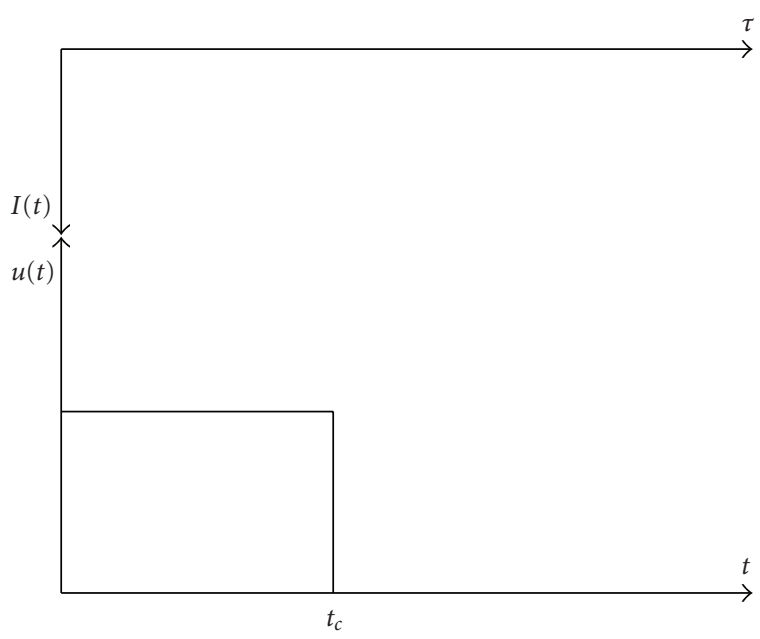

FIGURE 1: Impulse response function of a catchment.

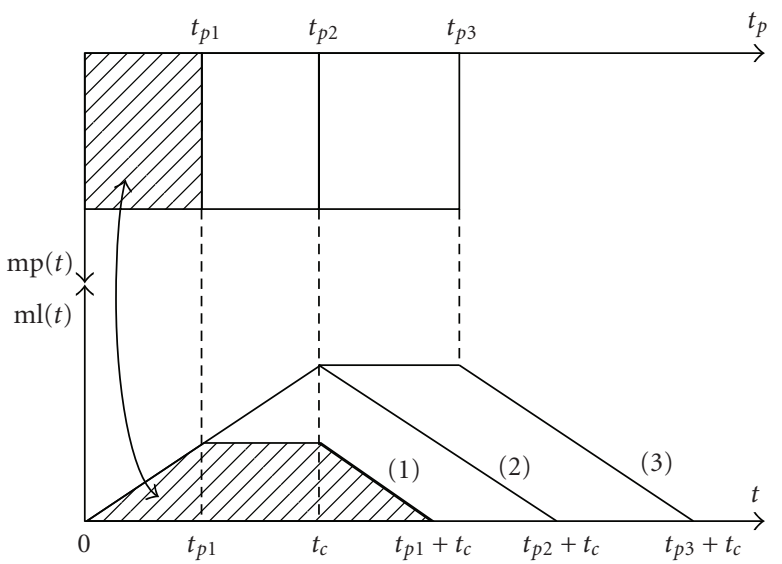

FIGURE 2: TSS pollutograph from the RQSM for rainfall of duration (1) $t_{p}<t_{c}$, (2) $t_{p}=t_{c},(3) t_{p}>t_{c}$.

Equations (3) and (4) show that erosion of solid particles is controlled by parameter $\mathrm{Kp}$ imp for impervious areas and by parameter $\mathrm{Kp}_{\mathrm{per}}$ for pervious areas. The infiltration process on pervious areas of urban catchments is often represented with Horton's model [24]. This model assumes that the infiltration capacity $(f)$ is equal to an initial value $\left(f_{0}\right)$ at the beginning of a rainfall event and then decreases exponentially to an asymptotic value $\left(f_{\infty}\right)$. The exponential decay of infiltration capacity is governed by a decay constant $(K)$.

3.3. Solid Particles Transport Model. Transport of solid particles by runoff is modeled using the linear system theory described by Chow et al. [25]. Solid particles transport is computed with the following convolution product:

$$
\operatorname{ml}(t)=\int_{0}^{t} \operatorname{mp}(\tau) u(t-\tau) d \tau,
$$

where $\mathrm{ml}$ represents the TSS load $(\mathrm{kg} / \mathrm{s}), \mathrm{mp}$, the erosion intensity $\left(\mathrm{kg} \cdot \mathrm{m}^{-2} \cdot \mathrm{s}^{-1}\right), u$, the impulse response of a catchment area $\left(\mathrm{m}^{2} / \mathrm{s}\right)$, and $t$, the duration $(\mathrm{s})$.
TABLE 1: Parameter reference values for the RQSM sensitivity analysis.

\begin{tabular}{lcccccccc}
\hline Parameters & $A$ & $\mathrm{IMP}$ & $t_{c}$ & $f_{0}$ & $f:$ & $K$ & $\mathrm{Kp}_{\text {imp }}$ & $\mathrm{Kp}_{\text {per }}$ \\
\hline Values & 100 & 0.5 & 32 & 160 & 16 & 4 & $2 \cdot 10^{-5}$ & $2 \cdot 10^{-5}$ \\
\hline
\end{tabular}

Figure 1 presents the impulse response of a catchment. It is assumed that the transport time of solid particles is equal to the transport time of liquid particles. Consequently, the catchment response is constant, and its duration is equal to the time of concentration $\left(t_{c}\right)$.

The pollutograph calculated by (5) for constant erosion intensity of duration $t_{p}$ is shown in Figure 2. Three different pollutographs are obtained at the outlet of the catchment, following the duration of the erosion process. The pollutograph (1) corresponds to the case $t_{p}<t_{c}$. Here, the simulated TSS load increases up to $t_{p}$. At that moment, a proportion $t_{p} / t_{c}$ of the catchment makes a contribution at the outlet. Then, the load remains constant up to $t_{c}$ due to the contribution made by the upper portion of the catchment. The pollutograph (2) corresponds to case $t_{p}=t_{c}$. In this case, the TSS load increases up to $t_{c}$. At that moment, the load is at its maximum since the entire catchment contributes at the outlet of the catchment. The pollutograph (3) corresponds to case $t_{p}>t_{c}$. In this case, the TSS load increases up to $t_{c}$. The load then remains constant up to $t_{p}$ since the erosion continues after $t_{c}$, throughout the entire catchment area. A study of the pollutographs provided by (5) prompts two comments. Firstly, the TSS mass generated by (5) always equals the eroded mass off TSS. Secondly, the simulated pollutograph duration always equals the sum of $t_{p}$ and $t_{c}$.

Rainfall intensity is always sampled in discrete time. Consequently, (1) should be expressed as follows:

$$
\begin{aligned}
\mathrm{ml}(t n)= & \overbrace{\sum_{i=1}^{t n \leq t p}\left[\mathrm{mp}_{\mathrm{imp}}(i) u_{\mathrm{imp}}\left(t_{n}-i+1\right)\right] \Delta t}^{\mathrm{ml}_{\text {imp }}(t n)} \\
& +\overbrace{\sum_{i=1}^{t n \leq t p}\left[\mathrm{mp}_{\mathrm{per}}(i) u_{\mathrm{per}}\left(t_{n}-i+1\right)\right] \Delta t}^{\mathrm{ml}_{\mathrm{per}}(t n)}
\end{aligned}
$$

with

$$
\begin{aligned}
& u_{\mathrm{imp}}\left(t_{n}-i+1\right) \\
& =\frac{10000 \mathrm{IMP} A}{t_{c}} \text { for } 1 \leq\left(t_{n}-i+1\right) \Delta t \leq t_{c}, \\
& u_{\mathrm{per}}\left(t_{n}-i+1\right) \\
& =\frac{10000(1-\mathrm{IMP}) A}{t_{c}} \text { for } 1 \leq\left(t_{n}-i+1\right) \Delta t \leq t_{c},
\end{aligned}
$$

where $u_{\text {imp }}$ represents the impervious area impulse response $\left(\mathrm{m}^{2} / \mathrm{min}\right) ; u_{\mathrm{per}}$, the pervious area impulse response $\left(\mathrm{m}^{2} / \mathrm{min}\right) ; A$, the catchment area (ha); IMP, the fraction of the impervious area; $t_{c}$, the time of concentration $(\mathrm{min}) ; t_{n}$, $t_{p}$, and $i$, time indices. 


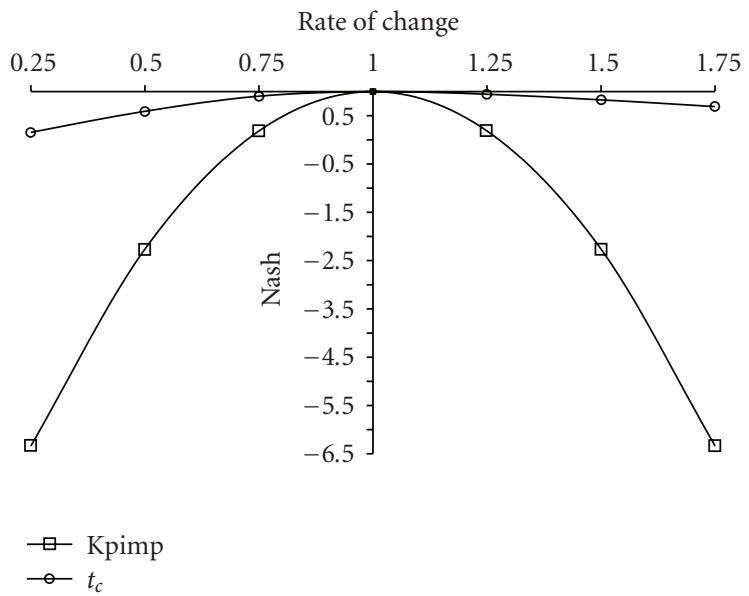

(a)
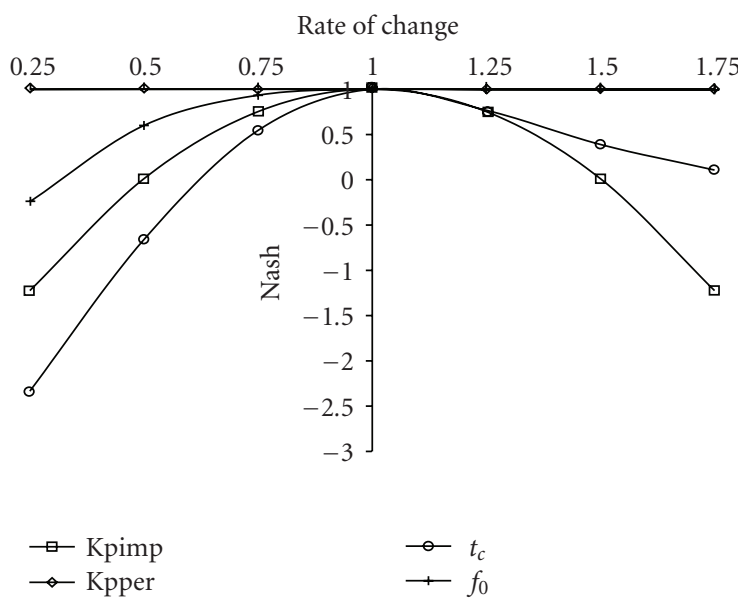

(b)

FIGURE 3: Variation of the Nash criterion with the rate of change of the RQSM parameters for (a) rainfall (1) and (b) rainfall (2).

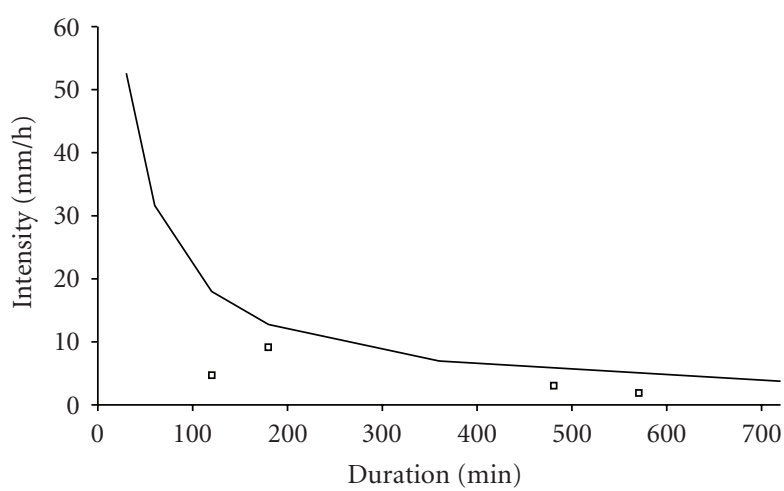

- IDF $T=2$ years

- Verdun

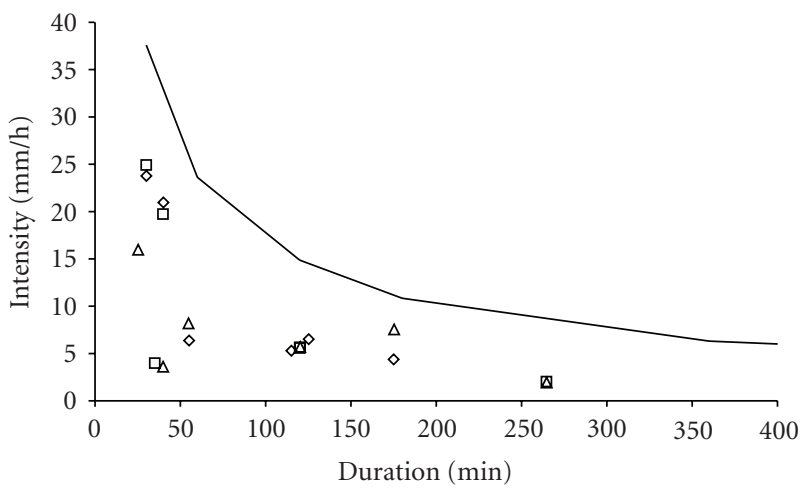

$\begin{array}{ll}- \text { IDF } T=0.5 \text { years } & \Delta \text { South Mattis } \\ \square \quad \text { North Mattis } & \diamond \text { North John }\end{array}$

(b)

FIGURE 4: Intensity Duration Frequency (IDF) of rainfall events monitored in (a), Verdun borough catchment and (b), North Mattis, South Mattis, and North John catchments.

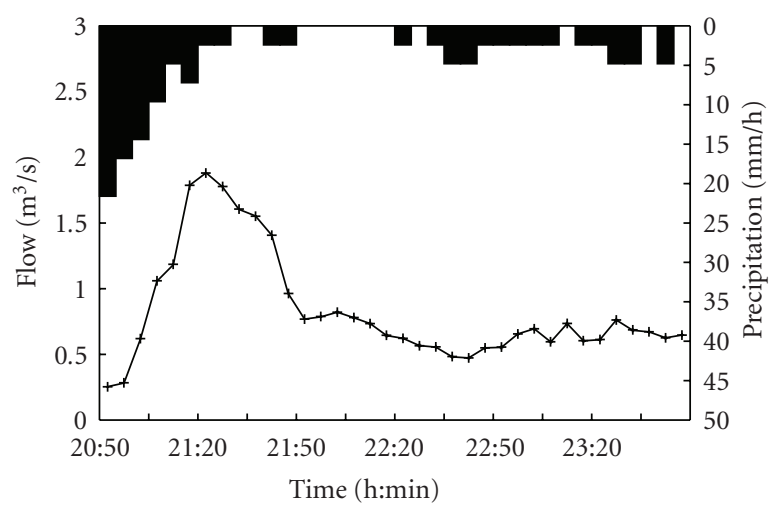

Precipitation $\leftarrow$ Monitored flow

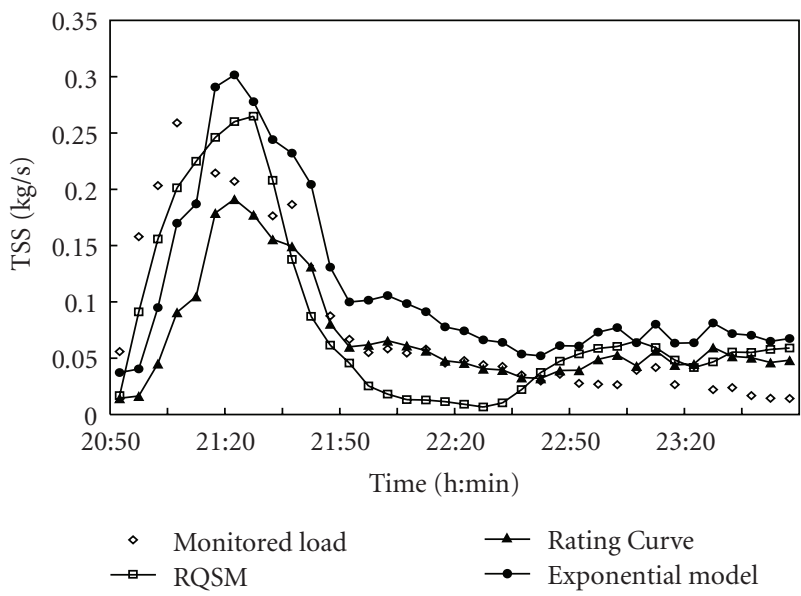

(b)

FIGURE 5: (a) Monitored rainfall and runoff, and (b) simulated TSS pollutographs for October 13, 2000 rainfall event in the Verdun borough. 


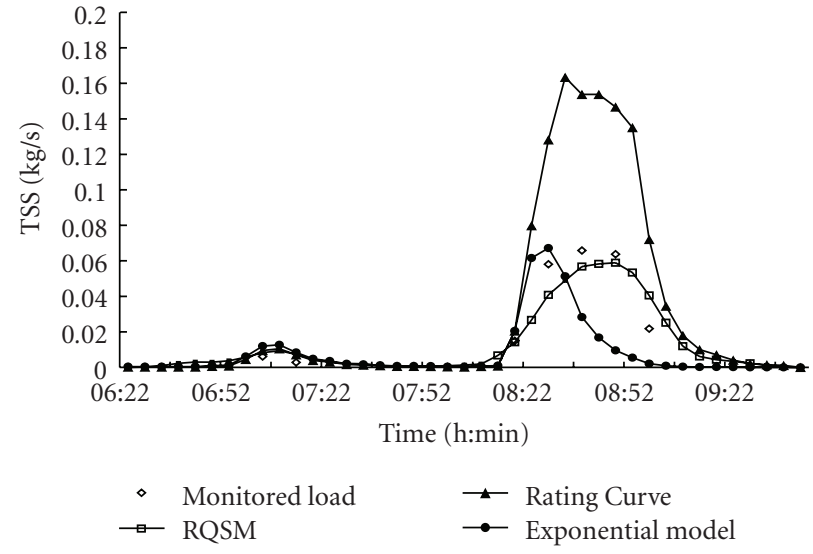

(a)

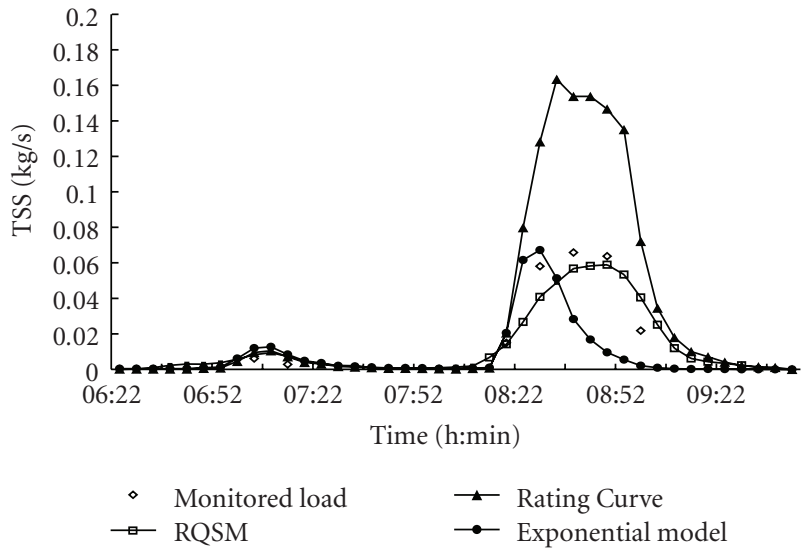

(b)

FIGURE 6: (a) Monitored rainfall and runoff, and (b) simulated TSS pollutographs for June 23, 1980 rainfall event in South Mattis.

TABLE 2: Physical characteristics of the four urban subcatchments used for the RQSM validation.

\begin{tabular}{|c|c|c|c|c|c|c|c|c|}
\hline Areas & Land use & $\begin{array}{c}A \\
\text { (ha) }\end{array}$ & IMP & $\begin{array}{c}t_{c} \\
(\mathrm{~min})\end{array}$ & $\begin{array}{l}\text { Slope } \\
(\mathrm{m} / \mathrm{m})\end{array}$ & $\begin{array}{c}f_{0} \\
(\mathrm{~mm} / \mathrm{h})\end{array}$ & $\begin{array}{c}f: \\
(\mathrm{mm} / \mathrm{h})\end{array}$ & $\begin{array}{c}K \\
\left(\mathrm{~h}^{-1}\right) \\
\end{array}$ \\
\hline Verdun & Residential & 177.0 & 0.39 & 37 & 0.005 & 85 & 25 & 2 \\
\hline North Mattis & Commercial & 6.8 & 0.58 & 30 & 0.004 & 200 & 33 & 2 \\
\hline South Mattis & Commercial & 11.2 & 0.40 & 18 & 0.010 & 200 & 33 & 2 \\
\hline North John & Residential & 22.1 & 0.19 & 24 & 0.006 & 200 & 33 & 2 \\
\hline
\end{tabular}

The conditions $\operatorname{mp}_{\text {imp }}(i) \geq 0, \operatorname{mp}_{\text {per }}(i) \geq 0$ must be respected. The notation $t_{n} \leq t_{p}$ as the upper limit of the summation indicates that the terms are summed for $i=1$ to $t_{n}$ when $t_{n} \leq t_{p}$, whereas, for $t_{n}>t_{p}$, the summation is limited to $i=1$ to $t_{p}$.

The TSS load from impervious areas $\left(\mathrm{ml}_{\mathrm{imp}}\right)$ and pervious areas $\left(\mathrm{ml}_{\text {per }}\right)$ is computed independently. Moreover, the RQSM uses rainfall intensity as the only explanatory variable of TSS transport.

\section{Sensitivity Analysis of the RQSM}

A sensitivity analysis was carried out on the RQSM in order to assess practical use and limitations. The sensitivity analysis involves determining the change of the RQSM response to the change of its parameters. The set of parameters presented in Table 1 is assigned to the RQSM in order to compute a reference pollutograph. The level of change between simulated and reference runoff pollutograph is evaluated with the following performance criteria:

(i) the Nash coefficient [26]:

$$
\text { Nash }=1-\frac{\sum_{i=1}^{n}\left(\mathrm{ml}_{\text {reference }}(i)-\mathrm{ml}_{\text {simulated }}\right)^{2}}{\sum_{i=1}^{n}\left(\mathrm{ml}_{\text {reference }}(i)-\overline{\mathrm{ml}}_{\text {reference }}\right)^{2}}
$$

A Nash of 1 indicates a perfect agreement between simulated and reference pollutograph.
The sensitivity analysis was conducted using the two following rainfall events:

(i) Rainfall (1): $I=10 \mathrm{~mm} / \mathrm{h}$; duration: $240 \mathrm{~min}$,

(ii) Rainfall (2): $I=80 \mathrm{~mm} / \mathrm{h}$; duration: $25 \mathrm{~min}$.

Rainfall (1) generates a rainfall depth lower than the infiltration capacity of pervious areas, whereas rainfall (2) generates a rainfall depth higher than the infiltration capacity of pervious areas. As a result, rainfall event (1) creates washoff over impervious areas only, whereas rainfall (2) produces washoff over both pervious and impervious areas.

The results of the sensitivity analysis for rainfall (1) are presented in Figure 3(a). It appears that $\mathrm{Kp}_{\mathrm{imp}}$ has a major impact on the Nash value. Consequently, $\mathrm{Kp}_{\mathrm{imp}}$ must be very carefully calibrated. The modification of the time of concentration creates a slight decrease of the Nash. As a result, a value close to $t_{c}$ may be used for low-intensity rainfall events having a duration higher than the time of concentration.

The results of the sensitivity analysis for rainfall (2) are presented in Figure 3(b). Three major observations can be made. Firstly, the variation of the $\mathrm{Kp}_{\mathrm{imp}}$ parameter dramatically decreases the Nash value, just as it does for rainfall (1). On the other hand, while the Kpper parameter has a slight effect with rainfall (1), it becomes critical in extreme wet weather or over a pervious area with a low infiltration capacity. Secondly, the effect of the time of concentration is higher than the effect of $\mathrm{Kp}_{\text {imp }}$ when its duration is higher than the rainfall duration. On the other hand, the influence 
of the time of concentration decreases significantly when its duration is lower than the rainfall duration. Finally, a large variation in the initial infiltration capacity $\left(f_{0}\right)$ leads to a significant variation of the Nash value. Furthermore, the underestimation of the initial infiltration capacity has a higher influence than its overestimation. The asymptotic infiltration capacity $\left(f_{\infty}\right)$ and the decay constant $(K)$ have a negligible influence on the Nash value. These results corroborate the observations made during the sensitivity analysis of a hydrologic model of the SWMM software [27] using the Horton model to calculate infiltration.

\section{Rating Curve and Exponential Models}

The Rating Curve model and the Exponential model [7] were used as a basis of comparison to evaluate the performance of the RQSM since both are acknowledged conceptual models [4].

The Rating Curve model links the suspended particle load to the runoff rate. It is expressed as follows:

$$
\operatorname{ml}(t)=a Q(t)^{b}
$$

where $\mathrm{ml}$ represents the TSS load $(\mathrm{kg} / \mathrm{s}), Q$, the runoff rate $\left(\mathrm{m}^{3} / \mathrm{s}\right), a$, the washoff coefficient, and $b$, the adjustment coefficient.

The Rating Curve model uses the runoff rate as the only explanatory variable for solid particle erosion and transport. This formulation has a physical basis because the hydraulic shear constraint at the liquid-solid interface is related to the runoff rate. The Rating Curve model is often used as an alternative to more complex models.

The Exponential Washoff model is the solid particles erosion and transport model used in the SWMM software. It takes into account the accumulation of solid particles. The erosion and transport of solid particles is computed with the following equation:

$$
\operatorname{ml}(t)=\operatorname{Ma}(t) k Q(t)^{r}
$$

where $\mathrm{ml}$ represents the TSS load $(\mathrm{kg} / \mathrm{s})$, Ma the mass of accumulated solid particles $(\mathrm{kg}), Q$ the runoff flow $\left(\mathrm{m}^{3} / \mathrm{s}\right)$, $k$ the washoff coefficient, and $r$ the adjustment coefficient. During wet weather, changes in the mass of accumulated particles may be expressed by

$$
\operatorname{Ma}(t)=\operatorname{Ma}(0) e^{-k Q(t)^{r} t} .
$$

Assuming an instantaneous accumulation model such as the one recommended by Kanso et al. [20], the initial accumulation $\mathrm{Ma}(0)$ at the start of a rainfall event becomes an additional parameter to calibrate.

\section{Validation of the RQSM}

6.1. The Sites. The RQSM, the Rating Curve model, and the Exponential model were calibrated and validated using 285 samples of TSS load. These samples were monitored during 4 rainfall events [28] that occurred in the catchment of the Verdun borough in Canada and during 18 rainfall events [29] that occurred in three catchments of the City of Champaign in the USA. The rainfall intensity and flow were monitored at 5-minute time steps for all the 22 rainfall events. Figures 4(a) and 4(b) show that rainfalls recorded in the city of Champaign have a return period lower than 0.5 years, whereas rainfalls recorded in Verdun have a return period lower than 2 years. These rainfall events are not extreme events. Consequently, the rainfall kinetic energy was calculated according to the recommendations of Salles et al. [23], using $\alpha$ equal to 11 and $\beta$ equal to 1.24 . The pervious area infiltration capacity was computed with the Horton model. The moving curve concept of Huber and Dickinson [7] was used to take into account the amount of potential storage remaining in the soil.

Table 2 shows the physical characteristics of the four catchment areas. Areas, slopes, and land use are very different for each catchment. The infiltration parameters were monitored for the three catchments of the City of Champaign, whereas the infiltration parameters of the Verdun catchment and the time of concentration of the four catchments were estimated using a hydrological model [30]. Nevertheless, these values may also be obtained through the use of formulae or tabulated values [25].

6.2. Calibration of Washoff Models. The parameters to be calibrated are the $\mathrm{Kp}_{\mathrm{imp}}$ and $\mathrm{Kp}$ per coefficients of the RQSM, the $a$ and $b$ parameters of the Rating Curve model, and the $\mathrm{Ma}(0), k$, and $r$ parameters of the Exponential model.

The performance evaluation of a model can be carried out with the help of the following three criteria:

(i) the Nash coefficient,

(ii) the mass ratio:

$$
R_{m}=\frac{\text { Simulated mass of TSS }}{\text { Monitored mass of TSS }}
$$

(iii) the peak load ratio:

$$
R_{p}=\frac{\mathrm{ml}_{\mathrm{Max}}^{\text {simulated }}}{\mathrm{ml}_{\text {Max }}^{\text {monitored }}}
$$

In urban hydrology, an accurate runoff simulation is reached when the Nash is greater than 0.8. A Nash of 0.6 can be considered as a more realistic value for TSS load simulation since uncertainties surrounding TSS load measurement are higher than for flow measurement [31].

The Nash was used to calibrate the parameters of the three washoff models. Parameters were adjusted with the Nelder-Mead simplex algorithm [32] used in the MATLAB software in order to maximize the Nash coefficient.

The three TSS washoff models were calibrated on the Verdun catchment using 2 monitored pollutographs and on the catchments of the City of Champaign using 9 pollutographs. The Kpimp parameter of the Verdun and Champaign catchments was calibrated with a rainfall event having an intensity that did not exceed the pervious area 
TABLE 3: Parameter values after calibration of the RQSM, Rating Curve, and Exponential models.

\begin{tabular}{|c|c|c|c|c|c|c|c|}
\hline \multirow{2}{*}{ Areas } & \multicolumn{2}{|c|}{ Rating Curve } & \multicolumn{3}{|c|}{ Exponential model } & \multicolumn{2}{|c|}{ RQSM } \\
\hline & $a$ & $b$ & $\mathrm{Ma}(0)$ & $k$ & $r$ & $\mathrm{Kp}_{\mathrm{imp}}$ & $\mathrm{Kp}_{\text {per }}$ \\
\hline Verdun & $8.45 \cdot 10^{-2}$ & 1.29 & 2963 & $9.89 \cdot 10^{-2}$ & 1.14 & $7.66 \cdot 10^{-6}$ & $1.80 \cdot 10^{-5}$ \\
\hline North Mattis & 1.41 & 1.46 & 552 & 8.27 & 1.13 & $2.84 \cdot 10^{-5}$ & \\
\hline South Mattis & 1.05 & 1.44 & 100 & 38.54 & 1.36 & $7.57 \cdot 10^{-6}$ & \\
\hline North John & 2.26 & 2.15 & 273 & 112.25 & 2.88 & $1.41 \cdot 10^{-5}$ & \\
\hline
\end{tabular}

TAble 4: Performance criteria values after particle load simulation with the RQSM, Rating Curve (RC), and Exponential (EXP) models.

\begin{tabular}{|c|c|c|c|c|c|c|c|c|c|}
\hline \multirow[b]{2}{*}{ Rainfall event } & \multicolumn{3}{|c|}{ Nash } & \multicolumn{3}{|c|}{$R_{m}$} & \multicolumn{3}{|c|}{$R_{p}$} \\
\hline & $\mathrm{RC}$ & EXP & RQSM & $\mathrm{RC}$ & EXP & RQSM & $\mathrm{RC}$ & EXP & RQSM \\
\hline V. 30-09-99 & -0.05 & 0.48 & 0.25 & 0.71 & 0.99 & 0.66 & 0.51 & 0.55 & 0.56 \\
\hline V. 13-10-99 & 0.49 & 0.06 & 0.70 & 0.85 & 1.36 & 0.98 & 0.74 & 1.16 & 1.02 \\
\hline N. M. $17-05-80$ & 0.81 & 0.85 & 0.46 & 1.23 & 1.44 & 0.79 & 0.87 & 1.03 & 0.64 \\
\hline N. M. 23-05-80 & -2.39 & 0.12 & 0.89 & 3.22 & 2.24 & 1.13 & 2.49 & 1.56 & 1.24 \\
\hline N. M. 01-06-80 & -1.47 & -2.14 & 0.42 & 2.80 & 3.02 & 1.54 & 1.75 & 2.26 & 0.99 \\
\hline S. M. 01-06-80 & -0.22 & 0.92 & 0.52 & 2.37 & 1.32 & 1.29 & 1.97 & 1.26 & 0.69 \\
\hline S. M. 23-06-80 & -1.19 & 0.51 & 0.88 & 2.31 & 0.63 & 0.99 & 2.34 & 1.02 & 0.90 \\
\hline S. M. $28-06-80$ & 0.73 & 0.98 & -0.07 & 1.43 & 0.92 & 0.47 & 1.06 & 0.91 & 0.19 \\
\hline N. J. $17-05-80$ & 0.88 & 0.80 & 0.65 & 0.76 & 0.58 & 1.50 & 0.95 & 0.86 & 1.21 \\
\hline N. J. 30-05-80 & 0.90 & 0.76 & 0.88 & 0.73 & 0.54 & 1.03 & 0.94 & 0.81 & 0.82 \\
\hline N. J. 01-06-80 & 0.88 & 0.79 & 0.26 & 0.89 & 0.83 & 1.48 & 1.09 & 1.20 & 0.66 \\
\hline
\end{tabular}

infiltration capacity. Consequently, only impervious areas were subject to washoff. Then, the Kpper parameter of the Verdun catchment was calibrated using a rainfall event having an intensity that exceeded the pervious area infiltration capacity. The $\mathrm{Kp}_{\text {per }}$ parameter of the three catchments of the City of Champaign was not calibrated since none of the monitored rainfall events were able to create a washoff on pervious areas. Table 3 shows the calibrated parameters for the RQSM, the Rating Curve model, and the Exponential model. The accumulated mass $\mathrm{Ma}(0)$ of the Exponential model and the Kp imp erosion coefficient of the RQSM do not seem correlated with catchment area, slope, or land use presented in Table 2.

6.3. Performance Evaluation of Washoff Models. The 11 TSS pollutographs simulated with the RQSM, the Exponential (EXP) model and the Rating Curve (RC) model were compared to the corresponding 11 monitored pollutographs. The Nash, $R_{m}$, and $R_{p}$ values after simulation are shown in Table 4. The Nash coefficient is greater than 0.6 for six rainfall events simulated with the Exponential model and for five rainfall events simulated with the RQSM and Rating Curve model. Thus, all three models provided pollutographs close to the monitored pollutographs for $50 \%$ of the simulated rainfall events. The error on the simulated mass of TSS is less than 30\% for 6 rainfall events simulated with the RQSM and Rating Curve model and for 3 rainfall events simulated with the Exponential model. It appears therefore that the RQSM provides equivalent results to those of the Rating Curve model but better than those of the Exponential model. The error on the simulated peak load is lower than $30 \%$ for 8 rainfall events simulated with the Exponential model and for 6 rainfall events simulated with the RQSM and Rating Curve model. Consequently, the peak loads simulated with the RQSM were equivalent to those of the Rating Curve model but not as accurate as those simulated with the Exponential model.

Figures 5 and 6 show two rainfall events simulated with the RQSM, Exponential, and Rating Curve models. These two rainfall events demonstrate that a correlation between the hyetograph and the pollutograph is not necessary to obtain good results with the RQSM. On the other hand, a close correlation between hydrograph and pollutograph allows both the Exponential and Rating Curve models to simulate adequately the pollutograph shape. However, a close correlation does not necessarily give an accurate estimation of the TSS load, as shown in Figure 6(b) of the Rating Curve model.

Comparison of the three washoff models with singlerainfall events can hide disparities or biases in the results. In order to have a more accurate overview of the RQSM, Exponential, and Rating Curve models performance, the mean value and standard deviation of the Nash, $R_{m}$, and $R_{p}$ data are presented in Table 5 . The number of simulated rainfall events are insufficient to statistically demonstrate the better performance of one of the three washoff models. Nonetheless, some interesting qualitative observations can be made. Firstly, the three models do not perfectly simulate the TSS load. Indeed, the Nash mean is less than 0.6, and the standard deviation is higher than 0.3. Secondly, the Exponential model and the Rating Curve model seem to overestimate the load of TSS. Indeed, the mean $R_{m}$ 
TABLE 5: Mean and standard deviation of the Nash, $\mathrm{R}_{P}$, and $\mathrm{R}_{M}$ values.

\begin{tabular}{|c|c|c|c|c|c|c|}
\hline \multirow[b]{2}{*}{ Models } & \multicolumn{2}{|c|}{ Nash } & \multicolumn{2}{|c|}{$R_{m}$} & \multicolumn{2}{|c|}{$R_{p}$} \\
\hline & Mean & Standard deviation & Mean & Standard deviation & Mean & Standard deviation \\
\hline Rating Curve & -0.06 & 1.14 & 1.57 & 0.93 & 1.34 & 0.68 \\
\hline Exponential & 0.33 & 0.93 & 1.26 & 0.77 & 1.15 & 0.45 \\
\hline RQSM & 0.53 & 0.31 & 1.08 & 0.35 & 0.81 & 0.31 \\
\hline
\end{tabular}

is close to 1 for the RQSM, whereas it is equal to 1.26 for the Exponential model and 1.57 for the Rating Curve model. Thirdly, the RQSM seems to underestimate peak load, while the Exponential model and the Rating Curve model overestimate it. Finally, the performance of the three washoff models varies greatly between each simulated rainfall event. Indeed, the standard deviation of Nash, $R_{m}$, and $R_{p}$ data ranged from 0.31 to 1.14 . These results are the consequence of four different sources of uncertainty. The first source of uncertainty is associated with rainfall, runoff, and TSS load measurement [31]. The second source of uncertainty stems from the lack of knowledge for the accumulation process of solid particles on impervious areas during dry weather. Finally, roughness, slope, and solid particle distribution is not uniform over the catchment area.

\section{Conclusion}

This paper sheds light on an original conceptual approach for modeling TSS load in urban areas. The originality of the RQSM lies in the use of rainfall kinetic energy to model solid particle erosion and the use of linear systems theory to describe the transport of suspended particle (TSS) to the catchment outlet.

The RQSM offers three advantages. Firstly, it calculates the TSS washoff load at the outlet of an urban area by using monitored rainfall intensity only. Secondly, it takes into consideration the contribution of suspended particles from pervious and impervious areas separately. Finally, the RQSM requires calibration of only two parameters.

A sensitivity analysis was conducted on the RQSM. The Nash coefficient was used to evaluate the influence of each parameter of the RQSM. The sensitivity analysis results show that, for rainfalls of high intensity and short duration, the most sensitive parameter is the time of concentration, whereas, for rainfall event of low intensity and long duration, the most sensitive parameter is the erosion parameter of impervious areas.

The first validation step was to calibrate the two RQSM erosion parameters, using 11 monitored pollutographs of TSS. The erosion parameter of impervious areas was calibrated with a low-intensity rainfall, and the erosion parameter of pervious areas was then calibrated with a highintensity rainfall.

The second validation step was to simulate the TSS load resulting from other 11 rainfall events. The loads simulated by the RQSM were compared to the monitored load and then to the load simulated with the Rating Curve and the SWMM Exponential model. Comparisons were made using three performance criteria: the Nash, the ratio of the simulated over the measured mass of TSS $\left(R_{m}\right)$, and the peak load ratio $\left(R_{p}\right)$. Equivalent results were obtained between TSS load computed with the RQSM and load computed with the Rating Curve and the SWMM Exponential model.

The encouraging results obtained with the RQSM on TSS washoff would suggest an extension of its use to the modeling of other pollutants.

\section{References}

[1] Environmental Protection Agency, "A screening assessment of potential impacts of climate changes on combined sewer overflow (CSO) mitigation in the Great Lakes and New England regions," EPA/600/R-07/033F, 2008.

[2] G. Chebbo and A. Bachoc, "Characterization of suspended solids in urban wet weather discharges," Water Science and Technology, vol. 25, no. 8, pp. 171-179, 1992.

[3] A. G. Jack, M. M. Petrie, and R. M. Ashley, "The diversity of sewer sediments and the consequences for sewer flow quality modelling," Water Science and Technology, vol. 33, no. 9, pp. 207-214, 1996.

[4] V. A. Tsihrintzis and R. Hamid, "Modeling and management of urban stormwater runoff quality: a review," Water Resources Management, vol. 11, no. 2, pp. 137-164, 1997.

[5] W. M. Alley and P. E. Smith, "Estimation and accumulation parameters for urban runoff quality modeling," Water Resources Research, vol. 17, no. 6, pp. 1657-1664, 1981.

[6] E. Servat, "Contribution à l'étude des matières en suspenion du ruissellement pluvial à l'échelle d'un petit bassin versant urbain," Montpellier, France, Thèse USTL, p. 182, 1984.

[7] W. C. Huber and R. E. Dickinson, "Storm Water Management Model: User's Manual. Version 4. EPA/600/3-88/001a," Environmental Research Laboratory, U.S. Environmental Protection Agency, Athens, Ga, USA, 1988.

[8] M. Temimi and S. Bennis, "Prévision en temps réel des charges de polluants dans un réseau d'assainissement urbain," Revue des Sciences de l'Eau, vol. 15, no. 3, pp. 661-675, 2002.

[9] US Army Corps of Engineers, "STORM: storage, treatment, overflow, runoff model-User's manual," 723-S8L7520. Hydrologic Engineering Center, Davis, Calif, USA, 1977.

[10] G. D. Moys, M. P. Osborne, and J. A. Payne, "Mosqito1. Modelling of stormwater quality including tanks and overflows. Design specifications," Tech. Rep. SR 184, Hydraulics Research Limited, Wallingford, UK, 1988.

[11] B. R. Bicknell, J. C. Imhoff, J. L. Kittle, T. H. Jobes, A. S. Donigian, and R. C. Johanson, "Hydrological Simulation Program-Fortran, User's manual for version 11," EPA/600/R97/080. U.S. Environmental Protection Agency, National Exposure Research Laboratory, Athens, Ga, USA, p. 755, 1997.

[12] M. Zug, L. Phan, D. Bellefleur, and O. Scrivener, "Pollution wash-off modelling on impervious surfaces: calibration, 
validation, transposition," Water Science and Technology, vol. 39, no. 2, pp. 17-24, 1999.

[13] A. Deletic, C. Maksimovic, and M. Ivetic, "Modelling of storm wash-off of suspended solids from impervious surfaces," Journal of Hydraulic Research, vol. 35, no. 1, pp. 99-117, 1997.

[14] A. Deletic, R. Ashley, and D. Rest, "Modelling input of fine granular sediment into drainage systems via gully-pots," Water Research, vol. 34, no. 15, pp. 3836-3844, 2000.

[15] N. E. Driver and B. M. Troutman, "Regression models for estimating urban storm-runoff quality and quantity in the United States," Journal of Hydrology, vol. 109, no. 3-4, pp. 221236, 1989.

[16] T. K. Jewell and D. D. Adrian, "Statistical analysis to derive improved stormwater quality models," Journal of the Water Pollution Control Federation, vol. 54, no. 5, pp. 489-499, 1982.

[17] J. D. Sartor, G. B. Boyd, and F. J. Agardy, "Water pollution aspects of street surface contaminants," Journal of the Water Pollution Control Federation, vol. 46, no. 3, pp. 458-467, 1974.

[18] D. E. Barbé, J. F. Cruise, and X. Mo, "Modeling the buildup and washoff of pollutants on urban watersheds," Water Resources Bulletin, vol. 32, no. 3, pp. 511-519, 1996.

[19] M. C. Gromaire, La pollution des eaux pluiviales urbaines en réseau d'assainissement unitaire, caractérisitiques et origines, Ph.D. thesis, ENPC, Marne la Valleee, France, 1998.

[20] A. Kanso, B. Tassin, and G. Chebbo, "A benchmark methodology for managing uncertainties in urban runoff quality models," Water Science and Technology, vol. 51, no. 2, pp. 163 170, 2005.

[21] D. Butler, S. Thedchanamoorthy, and J. A. Payne, "Aspects of surface sediment characteristics on an urban catchment in London," Water Science and Technology, vol. 25, no. 8, pp. 1319, 1992.

[22] R. A. Young and J. L. Wiersma, "The role of rainfall impact in soil detachment and transport," Water Resources Research, vol. 9, no. 6, pp. 1629-1636, 1973.

[23] C. Salles, J. Poesen, and D. Sempere-Torres, "Kinetic energy of rain and its functional relationship with intensity," Journal of Hydrology, vol. 257, no. 1-4, pp. 256-270, 2002.

[24] R. E. Horton, "An approach towards a physical interpretation of infiltration capacity," Proceedings of Soil Science Society of America, vol. 5, pp. 399-417, 1940.

[25] V. T. Chow, D. R. Maidment, and L. W. Mays, Applied Hydrology, McGraw-Hill, New York, NY, USA, 1988.

[26] J. E. Nash and J. V. Sutcliffe, "River flow forecasting through conceptual models part I-a discussion of principles," Journal of Hydrology, vol. 10, no. 3, pp. 282-290, 1970.

[27] S. Y. Liong, W. T. Chan, and L. H. Lum, "Knowledge-based system for SWMM runoff component calibration," Journal of Water Resources Planning and Management, vol. 117, no. 5, pp. 507-524, 1991.

[28] S. Bennis, "Caractérisation des eaux pluviales du secteur 1 de la ville de Verdun,” Tech. Rep., École de Technologie Supérieure, Ville de Verdun et BGH Planning, 2000.

[29] D. C. Noel, M. L. Terstriep, and C. A. Chenoweth, "Nationwide Urban Runoff program: data report," SWS Contract Report 410-1, Illinois State Water Survey, Department of Energy and Natural Resources, Champaign, Ill, USA, 1987.

[30] S. Bennis and E. Crobeddu, "La méthode rationnelle généralisée," Vecteur Environnement, vol. 38, no. 2, pp. 41-52, 2005.

[31] J. L. Bertrand-Krajewski, D. Laplace, C. Joannis, and G. Chebbo, Mesures en Hydrologie Urbaine et Assainissement, Éditions Tec \& Doc, Lavoisier, Paris, France, 2000.
[32] J. C. Lagarias, J. A. Reeds, M. H. Wright, and P. E. Wright, "Convergence properties of the Nelder-Mead simplex method in low dimensions," SIAM Journal on Optimization, vol. 9, no. 1, pp. 112-147, 1998. 

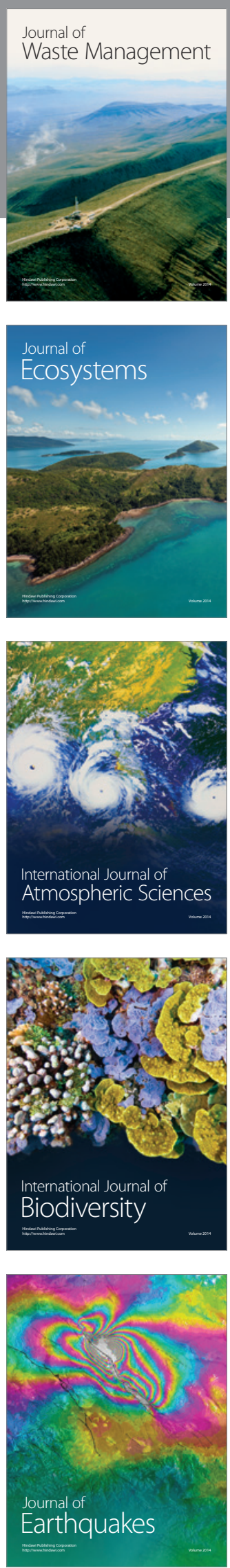
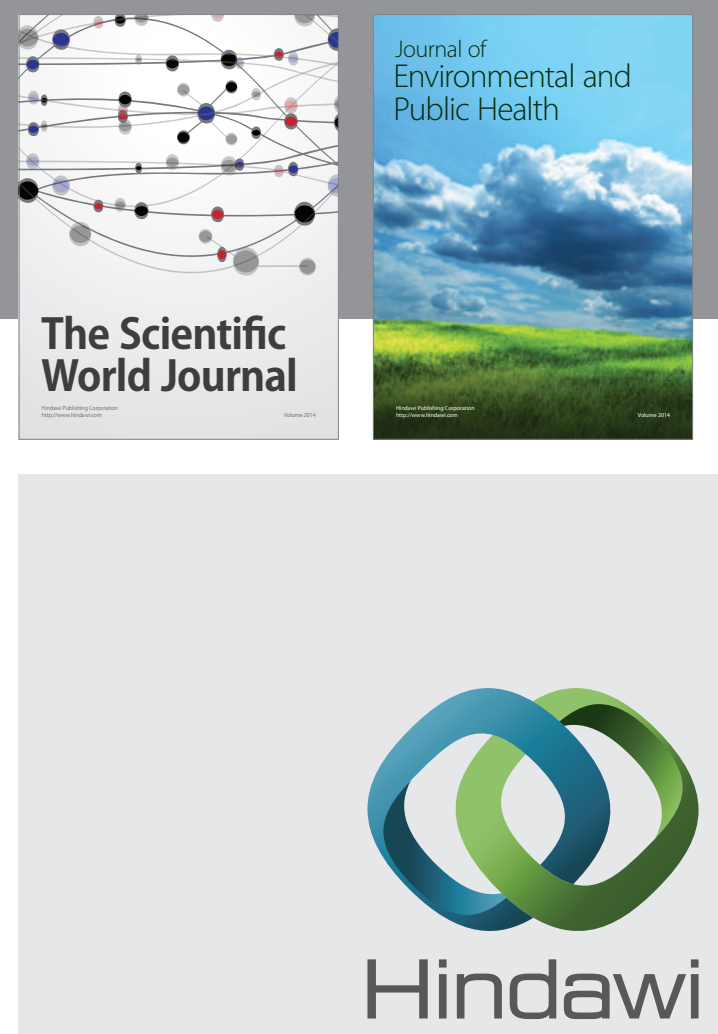

Submit your manuscripts at

http://www.hindawi.com
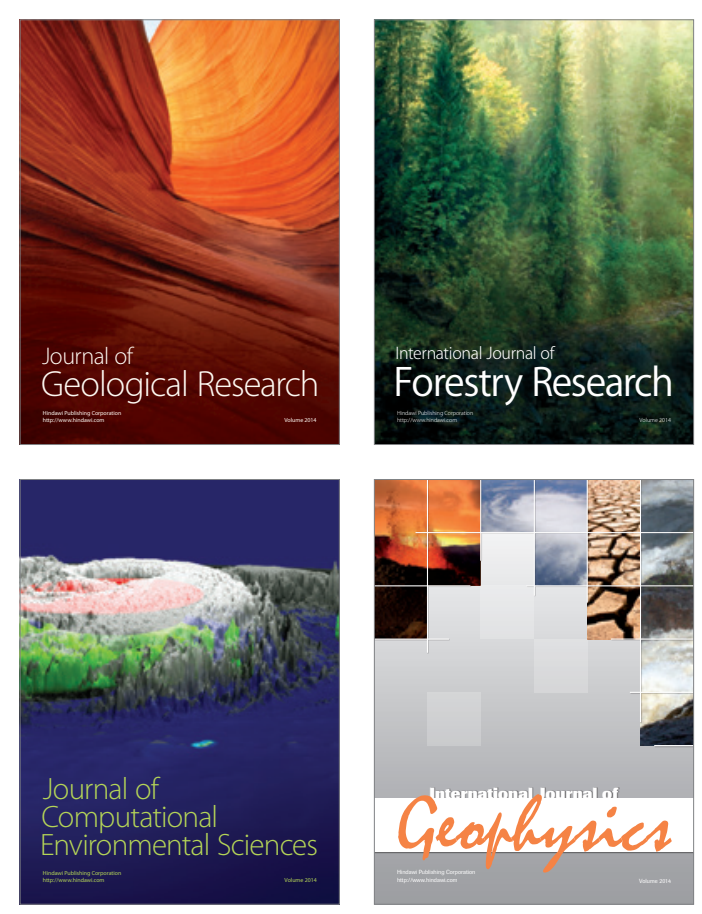
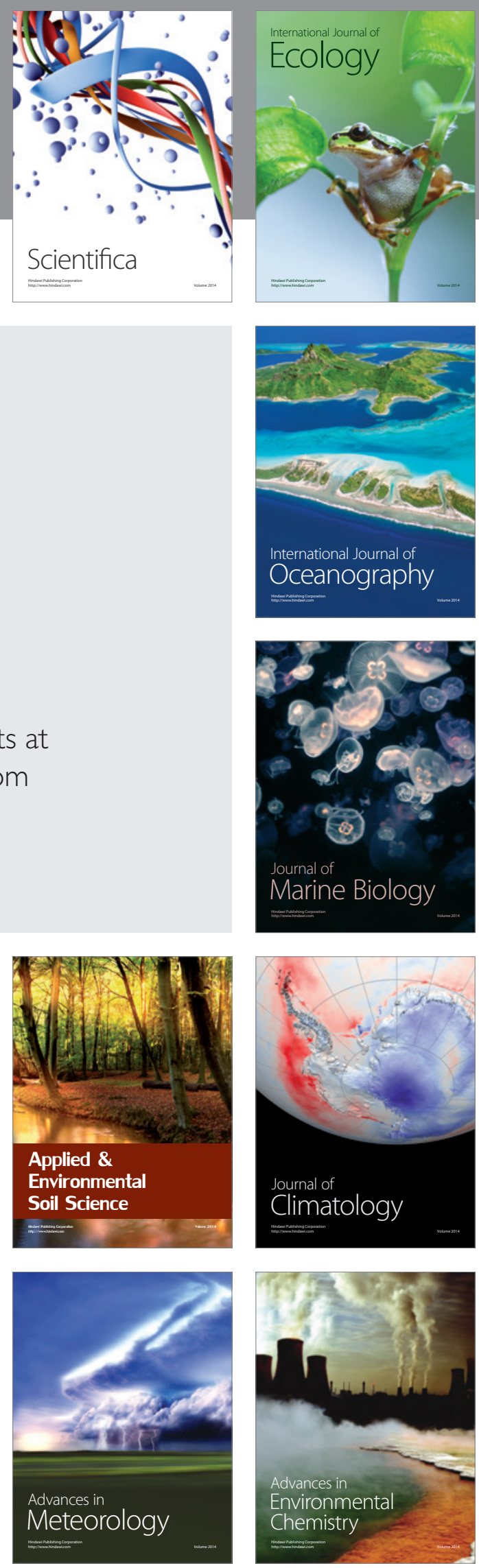